\title{
Percepção ambiental sobre as mudanças climáticas globais numa praça pública na cidade do Rio de Janeiro (RJ, Brasil)
}

\author{
Environmental perception on global climate change \\ in a public square in the city of Rio de Janeiro (RJ, Brazil)
}

\begin{abstract}
Alexandre de Gusmão Pedrini ${ }^{1}$. Daniel Shimada Brotto ${ }^{1}$. Thamyris Viana Santos ${ }^{1}$. Laís Lima $^{1}$ • Rosana Mendonça Nunes ${ }^{1}$
\end{abstract}

\begin{abstract}
Resumo: O entendimento do público sobre a problemática das Mudanças Climáticas Globais (MCGs) é pouco conhecido no Brasil. O entendimento obtido nessa pesquisa foi pela Percepção Ambiental Pública (PAP) de visitantes ao evento "Desapegue-se" ocorrido na Praça Edmundo Rego na cidade do Rio de Janeiro. Um questionário foi aplicado aleatoriamente para o estudo dos conceitos-chaves: a) Meio Ambiente (MA); b) Ambiente Marinho (AM); c) Educação Ambiental (EA); d) Mudanças Climáticas Globais (MCGs); e) Aquecimento Global (AG). Os resultados referem-se a dados coletados entre abril e julho de 2014. Foram 82 visitantes, sendo mulheres a maioria (66\%), com nível superior $(40 \%)$ e faixa salarial predominante de 2-5 salários mínimos. A maioria (entre 70 e $80 \%$ ) percebe adequadamente as MCGs, o AG, o MA e o AM. A EA é percebida apenas como mudança comportamental por 59\% do grupo de visitantes. Foi confirmada a hipótese de que esse público teria informação básica conceitual adequada. Cabe às escolas papel preponderante na apresentação e debate das MCGs.
\end{abstract}

Palavras-chave: Mudança climática. Oceano Atlântico. Percepção ambiental. Aquecimento Global. Rio de Janeiro.

\begin{abstract}
Public understanding about issues of Global Climate Change (GCC) is little known in Brazil. This understanding was analysed by Public Environmental Perception (PAP) of event visitors "Desapegue-se" (Let it Go) in Edmundo Rego Square in the city of Rio de Janeiro, Brazil. A questionnaire was randomly applied to study the key concepts of: a) Environment (E); b) Marine Environment (ME); c) Environmental Education (EE); d) Global Climate Changes (GCC); e) Global Warming (GW). The results cover from April-July 2014. There were 82 visitors: mostly women (66\%), with higher education $(40 \%)$ and prevailing salary range of 2-5 times the minimum wage. The majority (70-80\%) accurately responded: GCC, GW, E and ME. EE is only perceived as behavioural change by $59 \%$ of the visitors. The hypothesis that the public would have adequate conceptual information was confirmed. It is responsibility for the schools to lead the presentation and discussion of GCC.
\end{abstract}

Keywords: Climate change. Atlantic Ocean. Environmental perception. Global Warming. Rio de Janeiro.

\footnotetext{
${ }^{1}$ Universidade do Estado do Rio de Janeiro (UERJ), Instituto de Biologia Roberto Alcântara Gomes (IBRAG), Departamento de Biologia Vegetal (DBV), Rio de Janeiro, RJ, Brasil. E-mail: <pedrini@globo.com>.
} 


\section{Introdução}

As Mudanças Climáticas Globais (MCGs) são fatos inegáveis. No ambiente marinho a síntese de Brierley e Kingsford (2009) garante que um dos piores efeitos das MCGs é o Aquecimento Global (AG) e certamente causará a diminuição de espécies da biodiversidade marinha com reações negativas ainda não dimensionadas. Com o degelo das calotas polares e a consequente redução na densidade da água do mar, a circulação termohalina como conhecemos deixaria de existir, trazendo mudanças para a biodiversidade marinha, seja pela mudança nos padrões de dispersão como também das condições ambientais. O que mais preocupa é que a maioria das espécies e ecossistemas marinhos está atualmente submetida a várias ameaças concomitantes, a perda de biodiversidade ocorre em função de outros fatores que não cessaram sem uma mudança nos atuais padrões do "desenvolvimento econômico", que só virão com uma mudança na percepção e no comportamento da humanidade.

Preocupados com as afirmações de Brierley e Kingsford (2009) para o planeta, Turra et al. (2013) evidenciam os graves problemas causados pelas Mudanças Climáticas Globais especialmente pelo AG no ambiente marinho na América Latina. Mesmo reconhecendo que a inestimável riqueza da geobiodiversidade marinha ainda não tenha sido satisfatoriamente conhecida, ela ocorre profusamente na América Latina em seus 33 países e está sob risco imediato de perdas irreparáveis.

Em face dessa problemática, Turra et al. (2013) criaram a Rede de Monitoramento dos Ambientes Bênticos Costeiros (ReBentos) que abrange cerca de cem cientistas marinhos que atuam em grupos de trabalho (GT) específicos para cada ecossistema costeiro da América Latina. Ghilardi-Lopes, Kawabe e Slompo (2014) tendo como base essas orientações da ReBentos avaliaram a eficiência de um curso de extensão no contexto dos efeitos negativos da MCGs no mar. Suas conclusões evidenciaram efetividade em: (a) ampliar conhecimentos sobre as MCGs e seus efeitos nos ambientes costeiros e marinhos; (b) capacitar os professores para abordar as MCGs em sala de aula, aplicando técnicas diferenciadas de ensino e adotando objetos de aprendizagem baseadas em tecnologias de informações modernas.

Porém, para se planejar programas, projetos e ações para o cidadão e sua coletividade é necessário conhecer sua percepção sobre as MCGs. Maria, Cavalcanti e Eiró (2011) propõem que a percepção ambiental pública das MCGs independente dos variados paradigmas teóricos existentes está condicionada à percepção dos cidadãos sobre o meio ambiente (MA). As variadas interpretações do que significa MA podem pautar ações diferenciadas da humanidade em função dessa problemática. Cada cidadão elabora um significado específico sobre o MA. Desse modo, pesquisas sobre Percepção Ambiental Pública (PAP) são fundamentais, pois a percepção e a representação do MA estão visceralmente ligadas ao modo como o utilizamos. Maria, Cavalcanti e Eiró (2011) ainda defendem pesquisas de PAP no contexto das MCGs, pois possibilitam: (a) disponibilizar elementos para a compreensão dos mecanismos de opção e comportamentos sociais; (b) criar medidas adaptativas e políticas públicas que traduzam os variados contextos existentes identificando neles quais problemas são prioritários; (c) identificar quais elementos da subjetividade são mais importantes para compreender o impacto negativo das MCGs nas práticas culturais; (d) perceber que fatores influenciam sua forma de agir e interferir no nosso planeta; (e) evidenciar uma enorme sinergia entre a percepção e possíveis ações adaptativas; (f) implementar políticas públicas adequadas às características contextuais; (g) medir a predisposição pública a ações de 
enfrentamento e combate às MCGs; (h) mostrar a gravidade, natureza e possíveis efeitos negativos das MCGs pressentida pelas variadas sociedades; (i) identificar variadas percepções sobre as MCGs que possibilitem o encontro de diferentes perspectivas e o diálogo construtivo de saberes.

A PAP em países industrializados evidencia um relativo conhecimento do público quanto a essa problemática (BERK; SCHULMAN, 1995), porém, no Brasil, há restritos trabalhos nesse campo. Um estudo sobre a PAP com cerca de 400 estudantes num estado nordestino mostrou que o conhecimento sobre o AG era desprezível, sendo ele confundido com outros problemas gerais como a poluição comum (BARROS; PINHEIRO, 2013). Essas percepções podem também ser denominadas como representações sociais, segundo Moscovici (2007) ou simplesmente representações; podem abranger experiências, vocabulários, condutas ou conceitos; podem traduzir uma representação teórica de uma ciência certificada ou de um fato científico, mas que é dinâmico e está em permanente mutação. Então, estudos de PAP podem ser mais que meras coletas de opinião e sim abordagens de obtenção de conceitos derivados da construção de variadas representações de sujeitos. Nessa perspectiva, a PAP tem sido adotada, pressupondo a identificação e caracterização de representações sobre questões socioambientais. Assim, tem sido adotada como estratégia diagnóstica na identificação de fatos e conceitos que permeiem ações a serem promovidas pela EA.

A PAP almeja e possibilita a participação da população nas tarefas de gestão do espaço coletivo de uma unidade geográfica qualquer como a cidade do Rio de Janeiro por exemplo. Com as informações geradas pelas PAP ações posteriores de EA devem ser realizadas concomitantemente, tanto pela educação ambiental não formal (em espaços geográficos públicos), bem como, pela formal (em espaços escolares) ou informal (pela mídia). Nesse particular, Lükman (2006) reconhece que a relação entre a mídia e as MCGs não tem sido das melhores, pois traduz sempre esses fatos de maneira sensacionalista e superficial. De fato, as MCGs demandam uma discussão permanente nos espaços escolares, alertando sobre a manipulação das mídias, discutindo o modelo capitalista de consumo irrefletido e capacitando permanentemente os docentes para o enfrentamento e adaptação às MCGs.

Desse modo, este trabalho: aborda a PAP relativa às MCGs num espaço público, como entendido na perspectiva habermaisiana (HABERMAS, 1984), ou seja, um locus para pleitos coletivos, tanto a adultos como adolescentes; e, hipotetiza que ambientalistas - em evento dominical que prega sustentabilidade socioambiental numa praça pública -, possuem conhecimento conceitual básico adequado sobre as MCGs no mar.

\section{Referencial teórico}

As representações obtidas pelos estudos de percepção certamente indicam o que os sujeitos realizam em suas práticas cotidianas. Cada um deles têm entendimentos conceituais sobre MCGs, por exemplo. Então, suas vivências socioambientais possivelmente vão se agregar às suas experiências de vida marcadas por esses conceitos. É fato que não são apenas as representações que determinam as práticas cotidianas, mas, partindo delas pode-se incorporar novos entendimentos e visões de mundo, abrangendo novos padrões de interação entre o homem e seu meio (BISPO; OLIVEIRA, 2008). A seguir serão apresentados trabalhos emblemáticos selecionados sobre a PAP. 


\section{Percepção Ambiental da problemática por meios de conceitos-chaves}

Estudos sobre o conhecimento de alunos em escolas brasileiras sobre MCGs são incipientes. Contudo, é na escola que conhecimentos sobre as MCGs precisam ser abordados amplamente e apresentadas possibilidades de enfrentamento e adaptação pela coletividade. Tavares et al. (2010) estudaram o conhecimento de alunos de escolas em cidades do interior do estado de São Paulo. Verificaram que: (a) docentes de geografia das escolas desconhecem o AG; (b) os alunos têm como fonte de informação principal a TV e não as aulas na escola; (c) as respostas mais detalhadas sobre atitudes tomadas por eles para o enfrentamento do AG variaram enormemente, segundo a cidade; (d) os alunos têm um nível de conhecimento fraco sobre o tema, atingindo apenas $40 \%$ das respostas ideais. Então, as escolas estudadas, no estado mais importante e rico do país, estão despreparadas para enfrentar o flagelo do AG. Esse fenômeno, bem como, o das MCGs, está sendo apontado como o causador da falta de água que afeta o mundo atualmente. Cabe, então, aprofundar as pesquisas em espaço público - como escolas e praças públicas -, onde se deve pleitear uma abordagem mais efetiva sobre a temática. A PAP pode ser estudada por meio de várias abordagens metodológicas, sendo a percepção ambiental de conceitos-chave uma delas. Alguns conceitos-chaves da temática abordada serão apresentados a seguir.

\section{Mudanças Climáticas Globais (MCGs)}

As MCGs de origem antrópica são um tema complexo de se abordar com o público leigo. Em 1988 foi criado o Painel Intergovernamental sobre Mudança do Clima (em inglês: IPCC) em que um conjunto de cientistas oriundo dos países pertencentes à Organização das Nações Unidas (ONU) publicou relatórios técnicos em 1990 e em 1995, fornecendo as bases para a adoção do protocolo de Quioto (Japão) em 1997. Em 2001 o terceiro relatório foi publicado, mas, só com o quarto relatório (2007) juntamente com o uso de técnicas mais sofisticadas de análise de dados é que se pôde conhecer melhor o fenômeno das MCGs (antrópicas). O documento mais atual é o de 2014 (IPCC, 2014) em que as horríveis previsões apontadas anteriormente foram confirmadas. Assim, o nível de confiabilidade aumentou nas previsões modeladas, e com o aporte significativo de recursos financeiros, linhas de pesquisa propiciaram um conhecimento adequado que ensejam a tomada de decisões para adaptação e resiliência dos seres vivos. Porém, dentre as várias consequências nefastas o AG se destaca.

\section{Aquecimento Global}

Oliveira (2008) traduz como AG a elevação de quase 1 grau Celsius na temperatura média da superfície da Terra. Porém, esse efeito no mar e seus constituintes ainda tem sido motivo de intensas pesquisas científicas, mas as consequências previstas são péssimas. Orlando (2007) aponta que os dois piores efeitos diretos do AG no mar e que causarão a elevação do nível do mar são: (a) a elevação da temperatura dos oceanos; (b) o degelo das calotas polares e glaciares. Com isso as cidades costeiras serão alagadas. Sturmer, Trevisol e Boton (2010) pesquisaram estudantes de uma cidade rural do estado de Santa Catarina, e verificaram que o AG era o tema mais preocupante (97\%) dentre dez temas apresentados. Barros e Pinheiro (2013) 
Percepção ambiental sobre as mudanças climáticas globais ...

estudaram o entendimento de adolescentes do nordeste do Brasil e encontraram o mesmo baixo conhecimento sobre o tema. Os alunos entendem também que o AG é um dentre os vários problemas corriqueiros do planeta como a poluição, mas não o identificam no seu cotidiano.

\section{Meio Ambiente}

O conceito de MA varia enormemente. Munoz et al. (2009) mostraram no contexto de dezesseis países (maioria de europeus e africanos árabes) que respondentes europeus (franceses, alemães, italianos, entre outros), percebiam o MA preponderantemente sob a vertente preservacionista. No entanto, em países mais pobres do norte da África (Marrocos, Senegal e Tunísia) a percepção predominante foi pela vertente utilitarista. Depreende-se que essa percepção revela como o sujeito age, pensa, planeja e vive no MA. Estudos sobre a percepção das representações do construto de meio ambiente são relativamente frequentes no Brasil. A tipologia mais adotada quanto ao conceito de MA é a de Reigota (2007) organizada em três aspectos: (a) humanizante traduzida como "local da espécie humana"; (b) naturalizante como "local da natureza"; (c) integrador como "local de todos" (PEDRINI; LIMA; VIANA, 2016; PEDRINI et al., 2010). Em geral, cada conjunto de sujeitos tem entendimento específico sobre meio ambiente, sendo impossível apresentar um padrão geral.

\section{Ambiente Marinho (Mar)}

Estudos da percepção ambiental pública sobre o mar têm sido frequentes em países costeiros em outros continentes como a Austrália (TRENOUTH et al., 2012) e o Reino Unido (JEFFERSON et al., 2014), mostrando um conhecimento elevado sobre o ambiente marinho. Porém, nos EUA (BRODY, 1996) há cerca de 20 anos, o conhecimento era restrito. No Brasil, ao contrário, estudos sobre o conceito de mar são raros e variam enormemente. A maioria dos limitados estudados aponta para baixo conhecimento (PEDRINI et al., 2013; VASCONCELLOS; AMARAL; STEINER, 2008).

\section{Educação Ambiental}

A EA vem sendo tipificada e caracterizada, segundo os variados paradigmas que convivem contemporaneamente nesse campo multi ou transdisciplinar no Brasil. A proposta baseada em Pedrini (2007) parece ser de conceituação mais objetiva e operacionalmente simplificada. Ela pode ser apresentada como um processo pedagógico de transformação que proporcione emancipação política e financeira aos sujeitos submetidos a questões socioambientais que o oprimam. Com base nesses preceitos uma construção conceitual para a cidadania planetária pode ser cunhada. Internacionalmente, trabalhos como o de Kerry et al. (2011) provaram que campanhas pedagógicas planejadas com informação contextual e muita discussão técnica possibilitam programas eficazes de EA no contexto das MCGs na costa marinha canadense. Amaral et al. (2014) e Vasconcellos, Amaral e Steiner (2008) publicaram resultados mostrando a eficácia da EA com alunos de escolas do ensino fundamental para compreender os ambientes recifais marinhos do litoral pernambucano. Há limitadíssimos trabalhos sobre EA em MCGs (PEDRINI; SABA, 2008). 
Porém, a Educação Ambiental Transformadora e Emancipatória Freiriana, segundo Saito et al. (2014) possui pressupostos que criticam o modelo consumista de civilização que causa as MCGs. A EA calcada nos preceitos de Paulo Freire se configura como a mais qualificada para enfrentar essa problemática socioambiental que conduz nosso planeta a destruição que são as MCGs.

\section{Considerações}

A PAP é umas das estratégias metodológicas factíveis para se identificar entendimentos sobre temas socioambientais como as MCGs. Possibilita também que os sujeitos participem da gestão socioambiental do contexto em que estão cotidianamente. Em face da complexidade dos efeitos nefastos do AG e da necessidade de estudos de adaptação, vulnerabilidade e resiliência, a acomodação e inércia da humanidade são preocupantes. Pode tanto ser motivada pelo desconhecimento sobre o tema como pelo desinteresse dos empresários causadores do problema. Desse modo, é fundamental que se identifique as percepções da população de modo a combater eficazmente as causas e as consequências do AG em território brasileiro. Considerando que os ambientalistas têm maior domínio informacional sobre as questões que lhes cunham o nome, o presente trabalho pressupõe que os respondentes, presentes num evento socioambiental, possuem conceitos de MA, AM, EA e MCGs adequados. E daí pode-se exigir ações urgentes ao governo e mais políticas públicas no tema.

\section{A contribuição da mídia no contexto das MCGs}

Lükman (2006) foi uma das primeiras jornalistas que vinculou a EA com o jornalismo ambiental (JA). Identificou no JA um caráter sensacionalista por um lado e educativo por outro. Preferiu adotar o termo mídia-educação ambiental como estratégia teórico-metodológica para enfrentar e superar esse dualismo por ela identificado. Viu como sinônimo a educomunicação ambiental que tem inclusive uma política pública exclusiva. Conclui exortando uma melhor capacitação dos jornalistas nessa imbricação comunicação x educação x meio ambiente.

Quanto a fontes de informações usadas para o aprendizado sobre as MCGs há resultados variáveis. Porém, há uma visão uniformizada de que as MCGs são um problema para a humanidade. Um dos melhores trabalhos no contexto lusófono sobre o tema é o de Cabecinhas, Lázaro e Carvalho (2008) sobre práticas de consumo de mídia, uso de fontes de informação e representação das MCGs. Os autores pregam que os sujeitos investigados percebem as MCGs como um fato negativo e não sentem interesse favorável nesse tema. Para essa percepção os sujeitos se basearam em fontes de informação ligadas a jornais impressos de notícias a quem dão credibilidade científica. Silva et al. (2010) verificaram junto aos alunos do ensino médio em uma região do estado de São Paulo que a maioria busca a mídia televisiva seguida da impressa por jornal, sendo a internet de expressão menor.

A visão predominante das MCGs é a de alarmismo e as previsões catastróficas. Essa visão instiga a reflexão, tendo em vista a parcialidade da abordagem jornalística que contribui para uma visão equivocada. Souza (2012) entende a problemática que envolve as MCGs especialmente do AG como recorrente nos meios de comunicação de massas. O debate sobre AG é fortemente 
influenciado pela mídia comprometida com as instâncias de poder político. Isso impede o acesso aos verdadeiros debates científicos das MCGs, distorcendo a realidade e conduzindo o cidadão a formação de opinião inadequada.

\section{Área estudada}

O contexto público selecionado para realizar essa pesquisa foi uma praça-pública urbana que faz parte do cotidiano de cidades e bairros. Tem sido pobremente abordada para fins pedagógicos apenas como local de passagem ou de alocar peças pedagógicas para exposição passiva (SAITO, 2012). Assim, como esse contexto tem sido abordado de modo muito restrito pode ser uma possibilidade de se desenvolver metodologias participativas e lúdicas para se atuar nesse tipo de lugar público. Somando-se o contexto de praça pública ao do mar é uma experiência nova tanto pela PA como pela EA no campo da extensão universitária.

A pesquisa ocorreu na praça Edmundo Rego que está localizada no bairro do Grajaú, Rio de Janeiro (Figura 1) e é a principal praça do bairro. Nesta praça todo segundo domingo do mês (período matutino) ocorre o evento Desapegue-se - trata-se de uma feira de trocas de objetos e oferecimento de serviços -, que possui como base promover a ideia de sustentabilidade socioambiental.

Figura 1. Localização da Praça Edmundo Rego

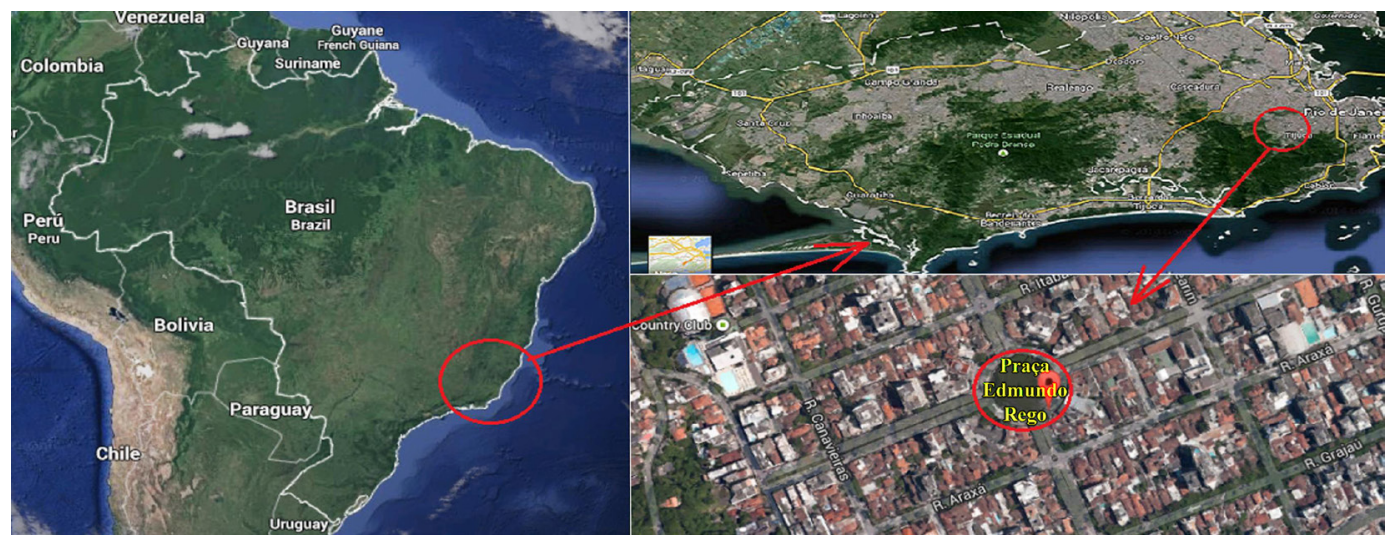

Fonte: Google Maps. Acesso em: 28 ago. 2014.

Tal feira aborda temas socioambientais com barracas oferecendo serviços socioambientais e doações/trocas de materiais variados. Nela encontram-se também barracas com serviços de alimentação orgânica e vegana, oficinas de alimentação crua e preparação de suco de clorofila, grupos de contação de estórias para crianças, trocas de livros, venda de bijuterias de sementes indígenas, doação de roupas e utensílios em gera, entre outros. 


\section{Materiais e métodos}

O conceito de praça pública adotado baseou-se no de esfera/espaço público de Habermas (1984) que a apresenta como espaço político para pleitos populares. O instrumento de coleta de dados e informações foi um questionário com dezoito questões (Anexo 1). Parte dos resultados foi apresentada em dois trabalhos de: (a) Pedrini et al. (2015) debatendo as atitudes e a responsabilidade do público pesquisado; (b) Pedrini, Lima e Viana (2016) caracterizando especialmente esses respondentes. No presente artigo são apresentados os entendimentos dos conceitos-chaves relacionados com a problemática abordada: (a) Meio Ambiente; (b) Educação Ambiental; (c) Ambiente Marinho; (d) Mudanças Climáticas Globais; (e) Aquecimento Global. O questionário foi aplicado aleatoriamente a 82 frequentadores da praça/evento durante quatro visitas de abril a julho de 2014. Cada respondente preencheu um Termo de Consentimento Livre e Esclarecido para uso de suas respostas, dados pessoais e imagens.

Os resultados textuais foram objeto de análise de conteúdo, segundo Franco (2005). As categorias de análise foram construídas previamente baseadas na literatura adotada. Em relação ao conceito de MA foram adotadas categorias baseadas em Reigota (2007): (a) humanizante traduzida como "local da espécie humana"; (b) naturalizante como "local da natureza"; (c) integrador como "local de todos". Quanto ao conceito de AM ou Mar as opções foram (sendo correta a primeira), segundo Pedrini et al. (2013): (a) "Ambiente com seres vivos, água, rochas, areias, interagindo"; (b) "Paisagem relaxante"; (c) "Ambiente com água salgada para lazer; (d) outra opção. Em relação ao conceito de EA as categorias foram adaptadas de Pedrini (2007), sendo desejadas as duas primeiras: (a) "Processo pedagógico que proporcione emancipação política e financeira dos homens (visão emancipatória)"; (b) "Processo pedagógico para mudar os hábitos das pessoas (visão transformadora)"; (c) "Palestras sobre meio ambiente (visão informativa)"; (d) "Dinâmicas sobre meio ambiente (visão lúdica)". Quanto ao conceito de MCGs (sendo correta a primeira) as opções foram: (a) "Alterações no clima causado pelo lançamento na atmosfera de gases maléficos, do desmatamento e incêndios florestais"; (b) "Alterações no clima da Terra causado por poluição aquática"; (c) "Outro”. Quanto ao conceito de AG (sendo correta a primeira), as opções foram: (a) "Aumento da temperatura no mundo devido às Mudanças Climáticas Globais (MCGs)"; (b) "Aumento da temperatura da Terra causado pela poluição do mar"; (c) "Alteração da temperatura da água do mar"; (d) "outra opção". O conceito de mídia não foi pesquisado aqui, mas os meios midiáticos ou de comunicação de informação, como: TV fechada ou aberta: internet, Jornal impresso, Livros, Revistas, Periódicos ou outras.

Os resultados numéricos derivados das ocorrências para cada categoria de análise foram incluídos em planilhas, somados e calculados suas frequências relativas. Em seguida, formulados quadros e gráficos pelo programa Excel e adotado o teste não paramétrico do Qui-quadrado $(\mathrm{p}<5 \%)$. 
Percepção ambiental sobre as mudanças climáticas globais ...

\section{Resultados}

\section{Perfil do público respondente}

Pedrini, Lima e Viana (2016) apresentaram as características do público pesquisado. Dos sujeitos estudados $66 \%$ eram do sexo feminino e $34 \%$ do sexo masculino. As pessoas com 24-33 anos (29\%) e da faixa de 34-43 (22\%), predominaram com 51\%, sugerindo serem sujeitos maduros. A escolaridade máxima obtida foi o nível superior (41\%) seguido pelo nível médio $(30 \%)$, totalizando $71 \%$ dos sujeitos. A faixa salarial predominantemente foi de $6-10(47 \%)$ salários mínimos (SM) seguida de 2-5 SM (42\%), totalizando $89 \%$ o que sugere inclusão na classe média. São pessoas de diferentes profissões, desde estudantes até funcionários públicos e empresários, nascidas predominantemente no Rio de Janeiro e residentes em diferentes bairros, sendo uma grande parte residente no bairro do Grajaú (onde ocorre a feira), e a maioria em bairros próximos a ele. A maior parte $(70 \%)$ dos respondentes já frequentou a praça mais de 5 vezes $(60 \%)$, seja por morar próximo ou em razão da feira.

\section{Percepções dos conceitos-chaves}

Foram registradas maiores frequências de respostas apropriadas sobre o conceito de MA marinho entre respondentes residentes no Grajaú. As pessoas com ocupações de nível superior demostraram um aparente padrão decrescente de respostas apropriadas de acordo com a maior remuneração e a idade, enquanto para escolaridade o padrão demonstrou-se crescente (Figura 2).

As maiores frequências dos que tem maior informação sobre as MCGs e AG ocorreram entre os que têm mídias impressas como principais fontes de informação, além de internet e de TV fechada principalmente. Desses, a TV fechada é a fonte de informação menos eficiente em disseminar conteúdos elucidativos sobre as MCGs e o AG. As frequências significativamente (Qui-quadrado, $p<5 \%$ ) superiores de respostas foram registradas para as respostas apropriadas sobre MCGs dos que leem mídias impressas. Com relação às mídias eletrônicas, as frequências significativamente (Qui-quadrado, $p<5 \%$ ) superiores foram registradas para as respostas apropriadas sobre as MCGs e AG dos que afirmaram que utilizam a internet como fonte de informações (Figura 3).

Quanto ao entendimento do significado de EA predominou a visão transformadora, tanto entre os que leem e os que não leem mídias impressas, porém com maior frequência entre os que leem mídias impressas. Já a visão emancipatória foi pouco frequente nas duas categorias e a visão informativa foi mais frequente entre os que não leem mídia impressa, com relação às mídias eletrônicas aparentemente a internet é a fonte de informações que mais propicia a visão emancipatória da EA entre os respondentes. A maior frequência de respostas, denotando a visão integradora do MA, ocorreu de forma proporcional entre os que leem e não leem mídias impressas. A visão humanizante só ocorreu para os que não leem mídias impressas e ela parece estar relacionada ao uso da TV fechada como fonte de informação. A visão integradora foi a mais frequente de maneira geral, principalmente entre os que utilizam a TV aberta e internet como fonte de informação (Figura 4). 
Figura 2. Frequências de respostas apropriadas e não apropriadas para o conceito de MA marinho de acordo com o bairro de moradia, ocupação, renda em salários mínimos, escolaridade e idade dos respondentes

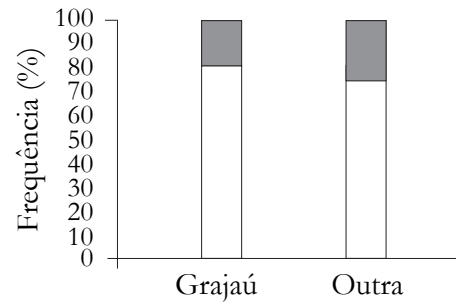

(34)

(48)

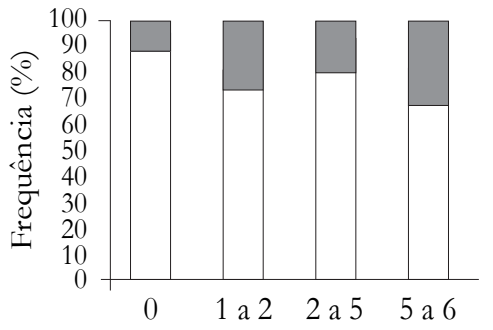

(16) (22) (35) (9)

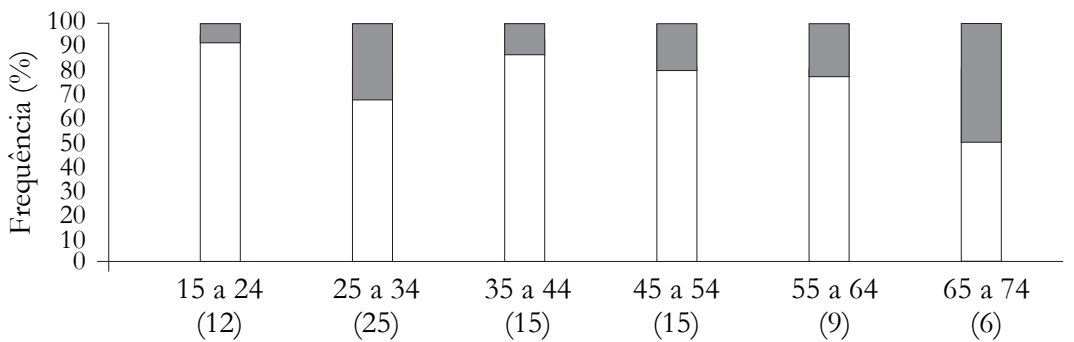

$\square$ Apropriada

Não apropriada

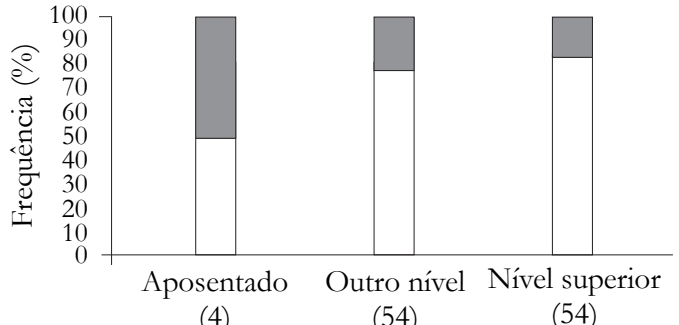

(4)

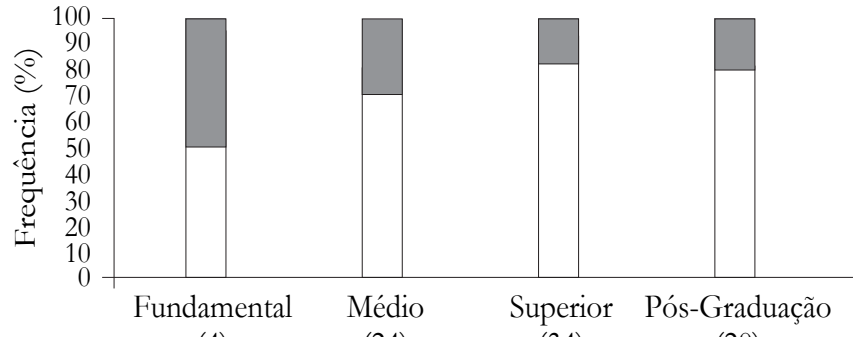

(4)

(24)

(34)

(20)

Fonte: elaborada pelos autores.

Aparentemente os fatores que mais condicionam os respondentes a uma noção apropriada sobre o Ambiente Marinho seriam residir no Grajaú, desempenhar ocupações que requerem o nível superior, além de obter remunerações medianas e possuir boa escolaridade. Também foi registrado que o uso da mídia impressa foi um fator importante para o melhor conhecimento do são as MCGs e AG, além de internet e de TV fechada. Parece que a TV fechada seria a fonte de informação menos eficiente em disseminar conteúdos elucidativos sobre as MCGs 
Figura 3. Frequências de respostas apropriadas e não apropriadas para o conceito de MCGs (esquerda) e AG (direita) de acordo com as fontes de informação na mídia impressa (acima) e eletrônica (abaixo) citadas pelos respondentes como suas fontes de informação
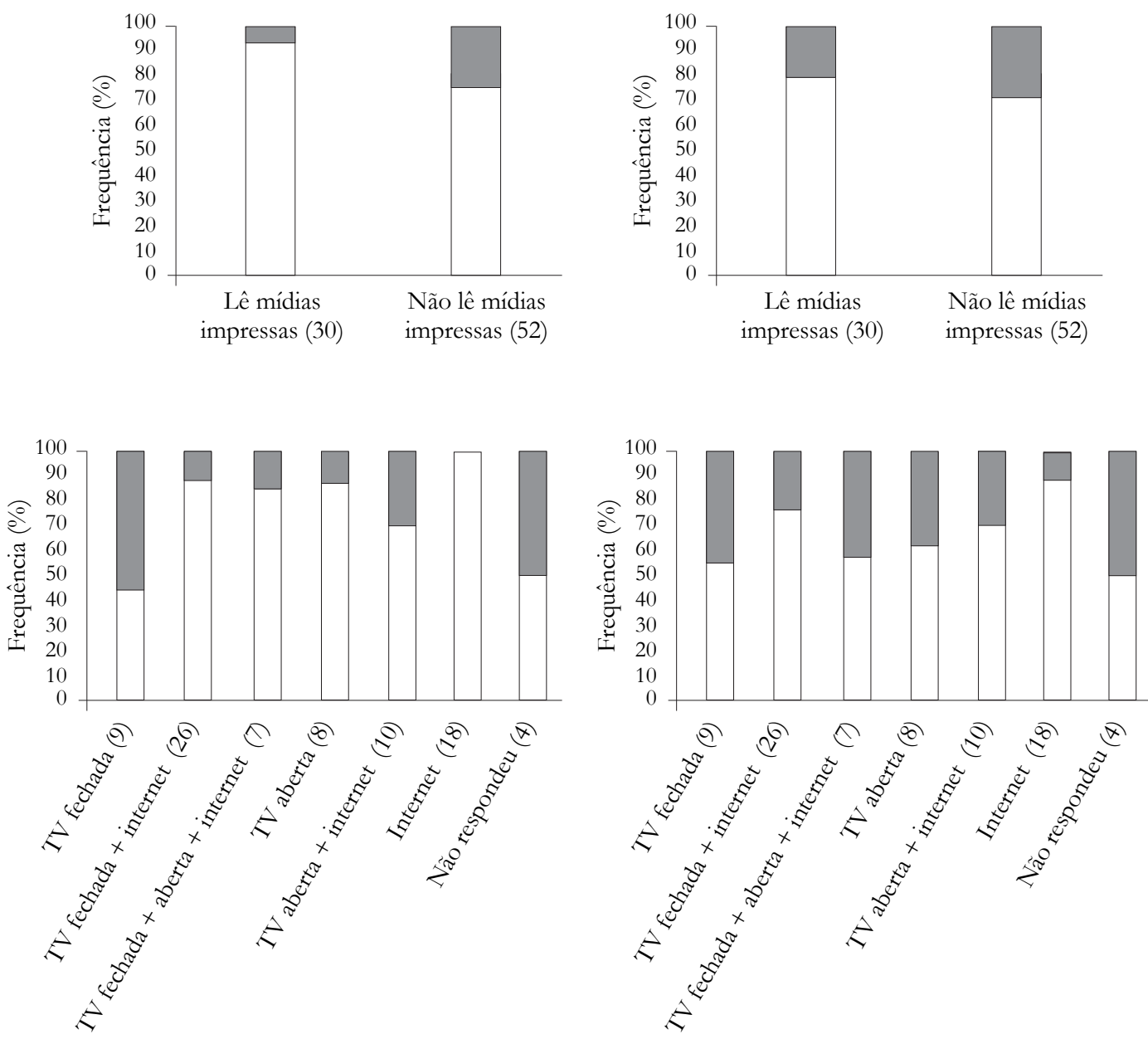

Apropriada

Não apropriada

Fonte: elaborada pelos autores.

e o AG. Observou-se o inverso quanto à noção do respondente sobre o significado de EA. Também com relação à visão sobre a EA, predominou a visão transformadora, tanto entre os que leem e os que não leem mídias impressas, porém, com maior frequência entre os que leem mídias impressas, aparentemente a internet, é a fonte de informações que mais propicia a visão emancipatória da EA entre os respondentes. 
Figura 4. Frequências de respostas demonstrando os diferentes entendimentos sobre EA (esquerda) e MA (direita), de acordo com suas fontes de informação na mídia impressa (cima) e eletrônica (embaixo) citadas pelos respondentes como suas fontes de informação
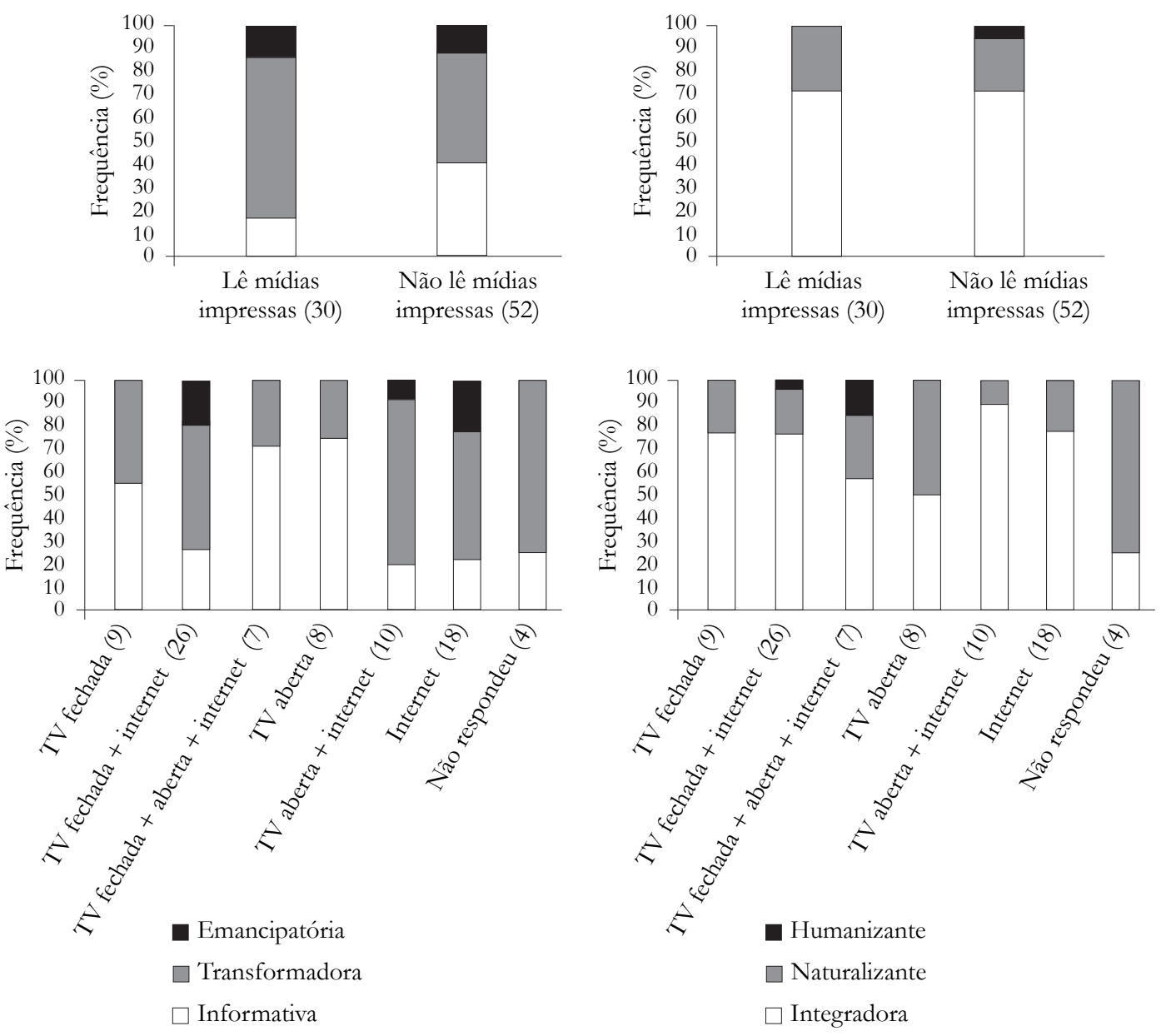

Fonte: elaborada pelos autores.

A visão integradora do MA ocorreu de forma proporcional entre os que leem e não leem mídias impressas. Foi mais frequente de maneira geral, principalmente entre os que utilizam a TV aberta e internet como fonte de informação. A visão humanizante só ocorreu para os que não leem mídias impressas e também parece estar associada ao uso da TV fechada como fonte de informação. 


\section{Discussão}

Os visitantes da praça pública, participantes do evento dominical "Desapegue-se", ao aceitarem participar de uma investigação sobre suas percepções socioambientais relativas às MCGs no mar traduzem sua preocupação com a problemática. Os entendimentos identificados dos sujeitos pesquisados que se revelaram nas representações expressadas demonstram preocupação com os efeitos maléficos derivados das MCGs. Como esses sujeitos também apresentaram um nível adequado de conceitos e conhecimento básico sobre os fenômenos, a hipótese de que o público de ambientalistas teria um nível de conhecimento condizente com seu perfil foi confirmada. Essas representações de formas, conteúdos e atitudes podem traduzir as experiências que cotidianamente vivenciam.

Os estudos brasileiros de percepção arrolados que mais aderiram ao escopo do presente trabalho mostraram divergência em termos de conhecimento conceitual quanto às MCGs. Em outros trabalhos o desconhecimento sobre as MCGs e o AG foi patente. O conhecimento confuso sobre o fenômeno e o desconhecimento de efeitos das MCGs no cotidiano dos alunos, foi indiferente quando formulados no nordeste (onde se pressupõe má qualidade de ensino em geral) ou na região sul (onde se pressupõe o oposto) (BARROS; PINHEIRO, 2013; STURMER; TREVISOL; BOTON, 2010), embora, esses autores tenham trabalhado com alunos do ensino médio e em sala de aula.

Os resultados do presente estudo mostraram um público com entendimento conceitual adequado, especialmente quanto as MCGs e AG diferentemente da literatura citada anteriormente. Essa divergência pode ter ocorrido pelos seguintes motivos: (1) público diferente - os do presente trabalho foram em sua maioria de pessoas mais velhas de 24-43 anos, em tese mais amadurecidas; (2) os sujeitos serem ambientalistas participantes/visitantes de um evento socioambiental; (3) nesta pesquisa foram oferecidas respostas mais elaboradas como opção de respostas, ensejando que os respondentes possam ter aprendido na hora ou acharem que as respostas maiores eram as mais convincentes. As mesmas suposições de explicação quanto às MCGs e AG podem ter ocorrido quanto ao conceito de AM.

Numa visão conjunta percebe-se que as representações de MA dos sujeitos estudados mostram uma perspectiva que traduz a compatibilização do todo, incluindo os seres humanos (REIGOTA, 2007). Essa perspectiva era a esperada e desejada, confirmando-se que os sujeitos de um evento socioambiental teriam um entendimento mais elevado que outros tipos de sujeitos. Em relação ao conceito de AM a percepção adequada de seus conceitos se assemelha ao que foi determinado para o público de países europeus (JEFFERSON et al., 2014; TRENOUTH et al., 2012). No entanto, contraria o que foi identificado por Vasconcellos, Amaral e Steiner (2008) e Pedrini et al. (2013) para o público brasileiro em que o conhecimento é baixo, tanto com estudantes como pelo grande público. Os resultados desta pesquisa denotam um público informado quanto a conceitos das MCGs. Porém, o principal motivo desse conhecimento avançado e inesperado pode ser em face da oferta de respostas bem elaboradas como opção de resposta. As dificuldades encontradas em algumas poucas questões para esse processo de pesquisa podem ter sido por dois motivos: (a) o instrumento de coleta ter sido considerado extenso, desmotivando-os; (b) participação numa ocasião de lazer dominical. Não se verificou nenhum padrão definitivo que possa ser generalizado quanto a entendimentos sobre conceitos específicos e fontes de informação adotadas. 
Essas características do público estudado permitem que realizem pleitos no tema abordado às autoridades que realizam a gestão socioambiental do espaço público. A Educação Ambiental Emancipatória e Transformadora que supera o modelo comportamental imediato em que só cabe mudanças individuais, ainda não foi totalmente compreendida pelo cidadão. Desconhecem o modelo mais avançado de EA como a de Paulo Freire que não aceita a proposta governamental de se adaptar e acomodar ao modelo opressor capitalista. O conceito de EA adequado para se encarar as MCGs é o de enfrentamento ao modelo civilizatório consumista contemporâneo. Então, com essa compreensão, a visão comportamental imediatista será superada em sua totalidade. Assim, a hipótese testada de que um público de ambientalistas presente num evento de sustentabilidade e desapego de materiais teria conhecimento conceitual adequado quanto aos construtos selecionados, foi aprovada.

\section{Considerações finais}

O público estudado apresentou um adequado conhecimento da maioria absoluta dos conceitos-chave abordados. Os sujeitos frequentadores de um evento de sustentabilidade socioambiental e de desapego de material, realizado em um espaço público, demandam aprofundamento na informação relacionada às MCGs e seus efeitos no mar. Essas informações e dados possibilitarão maior participação pública dos frequentadores da praça, tal como prevista na perspectiva habermaisiana. Essa participação coletiva reforça o protagonismo pleiteado pelos sujeitos para uma adequada gestão de enfrentamento às MCGs de origem antrópica. A Educação Ambiental Emancipatória e Transformadora Freiriana tem arcabouço teórico metodológico para implantar uma nova sociedade igualitária e saudável.

\section{Referências}

AMARAL, F. M. D. et al. The role of environmental education in changing school students' perceptions of and attitudes toward coral reefs in the Fernando de Noronha Archipelago, Brazil. Revista da Gestão Costeira Integrada, Lisboa, v. 14, n. 4, p. 581-590, 2014.

Disponível em: <http://www.aprh.pt/rgci/pdf/rgci-513_Amaral.pdf>. Acesso em: 9 set. 2016.

BARROS, H. C. L.; PINHEIRO, J. Q. Dimensões psicológicas do aquecimento global conforme a visão de adolescentes brasileiros. Estudos de Psicologia, Natal, v. 18, n. 2, p. 173-182, abr./jun. 2013. Disponível em: < http://www.aprh.pt/rgci/pdf/rgci-513_Amaral. pdf>. Acesso em: 9 set. 2016.

BERK, R. A.; SCHULMAN, D. Public perceptions of global warming. Climate Change, Dordrecht, v. 29, n. 1, p.1-33, 1995. 
Percepção ambiental sobre as mudanças climáticas globais ...

BISPO, M. O.; OLIVEIRA, S. F. Tecendo saberes, fazeres e práticas reflexivas a partir das representações de meio ambiente e educação ambiental de professores e estudantes. In: ENCONTRO NACIONAL DE PROGRAMAS DE PÓS-GRADUAÇÃO E PESQUISA EM AMBIENTE E SOCIEDADE, ENAMPPAS, 4., 2008, Brasília. Anais... Brasília, 2008. Disponível em: <http://www.anppas.org.br/encontro4/cd/ARQUIVOS/GT9-823-51520080510092649.pdf>. Acesso em: 28 fev. 2015.

BRIERLEY, A. S.; KINGSFORD, M. J. Impacts of climate change on marine organisms and ecosystems. Current Biology, Cambridge, v. 19, n. 14, p. R602-R614, 2009.

BRODY, M. J. An assessment of 4th-, 8th-, and 11th- grade students' environmental science knowledge related to Oregon's marine resources. The Journal of Environmental Education, Philadelphia, v. 27, n. 3, p. 21-27, 1996.

CABECINHAS, R.; LÁZARO, A.; CARVALHO, A. Media uses and social representations of climate change. In: CARVALHO, A. (Ed.). Communicating climate change: discourses, mediations and perceptions. Braga: Universidade do Minho, 2008. p. 170-189. Disponível em: <http://www.lasics.uminho.pt/ojs/index.php/climate_change/article/ view/421/390>. Acesso em: 03 out. 2014.

FRANCO, M. L. P. B. Análise de conteúdo. 2. ed. Brasília: Liber, 2005.

GHILARDI-LOPES, N. P.; KAWABE, L. A.; SLOMPO, C. S. Formação continuada em mudanças climáticas globais e seus efeitos nos ecossistemas marinhos e costeiros: um relato de experiência de curso de extensão na Universidade Federal do ABC (UFABC, Santo André, Brasil). Revista da SBEnBIO, Niterói, n. 7, p. 5935-5946, 2014. Disponível em: <http:// www.sbenbio.org.br/wordpress/wp-content/uploads/2014/11/R0107-1.pdf>. Acesso em: 03 out. 2014.

HABERMAS, J. Mudança estrutural da esfera pública: investigações quanto a uma categoria da sociedade burguêsa. Rio de Janeiro: Tempo Brasileiro, 1984.

IPCC. Cambio climático 2014: impactos, adaptación e vulnerabilidade, resumen para responsables de políticas. Genebra: Organización Metereológica Mundial, 2014. Disponível em: < https://www.ipcc.ch/pdf/assessment-report/ar5/wg2/ar5_wgII_spm_es.pdf>. Acesso em: 27 fev. 2015.

JEFFERSON, R. L. et al. Public perceptions of the UK marine environment. Marine Policy, Kidlington, v. 43, p. 327-337, 2014.

KERRY, J. et al. J. Les compétences d'adaptation aux changements climatiques démontrées par des employés municipaux d'une communauté côtière canadienne. Canadian Journal of Environmental Education, Thunder Bay, v. 16, p. 155-172, 2011. Disponível em: <https:// cjee.lakeheadu.ca/article/view/941/637>. Acesso em: 9 set. 2016.

LÜCKMAN, A. P. Jornalismo e mídia-educação no contexto do aquecimento global.

Estudos em Jornalismo e Mídia, Florianópolis, v. 3, n. 2, p. 55-67, 2006. Disponível em: $<$ https://periodicos.ufsc.br/index.php/jornalismo/article/view/2291/2018>. Acesso em: 27 fev. 2015. 
Pedrini, A. G; Brotto, D. S.; Santos, T. V.; Lima, L.; Nunes, R. M.

MARIA, J. A.; CAVALCANTI, I.; EIRÓ, F. H. Percepção ambiental e mudanças climáticas. In: ENCONTRO DA SOCIEDADE BRASILEIRA DE ECONOMIA ECOLÓGICA, 9., 2011, Brasília. Anais... Brasília, 2011. Disponível em: <http://www.ecoeco.org.br/ conteudo/publicacoes/encontros/ix_en/GT3-162-91-20110613132907.pdf>. Acesso em: 27 fev. 2015.

MOSCOVICI, S. Representações sociais: investigações em psicologia social. 5. ed. Petrópolis: Vozes, 2007.

MUNOZ, F. et al. Teachers' conceptions of nature and environment in 16 countries. Journal of Environmental Psychology, London, v. 29, n. 4, p. 407-413, 2009. Disponível em: <http://dx.doi.org/10.1016/j.jenvp.2009.05.007>. Acesso em: 27 fev. 2015.

OLIVEIRA, S. M. B. Base científica para a compreensão do aquecimento global. In: VEIGA, J. E. (Org.). Aquecimento global: frias contendas científicas. São Paulo: SENAC, 2008. p. 17-54. ORLANDO, B. Consequências esperadas. In: DOW, K.; DOWNING, T. E. (Org.). O atlas da mudança climática: o mapeamento completo do maior desafio do planeta. São Paulo: Publifolia, 2007. p. 53-68.

PEDRINI, A. G. Um caminho das pedras em educação ambiental. In: PEDRINI, A. G. (Org.). Metodologias em educação ambiental. Petrópolis: Vozes, 2007. p. 23-51.

PEDRINI, A. G.; SABA, M. G. Educação ambiental e mudanças ambientais globais: um relato de experiência com o documentário "uma verdade inconveniente" como estratégia no ensino de inglês numa escola pública. In: CONFERÊNCIA DA TERRA, 1., 2008, Recife. Anais... Recife: Conferência da Terra, 2008. p. 101-105. 1 CD-ROM.

PEDRINI, A. G.; LIMA, L.; VIANA, T. Percepção ambiental em praça pública como estratégia para enfrentamento do aquecimento global do mar: percepção dos visitantes sobre a problemática. In: FÓRUM BRASILEIRO DE EDUCAÇÃO AMBIENTAL, 8., 2016, Belém. Anais... Belém: Rede Brasileira de Educação Ambiental, 2016. 1 CD-ROM.

PEDRINI, A. G. et al. Educação ambiental pelo ecoturismo numa trilha marinha no Parque Estadual da Ilha Anchieta, Ubatuba (SP). Revista Brasileira de Ecoturismo, São Paulo, v. 3, n. 3, p. 428-459, 2010. Disponível em: <http://www.sbecotur.org.br/rbecotur/seer/index. php/ecoturismo/article/view/97>. Acesso em: 9 set. 2016.

Percepção ambiental pública sobre atitudes e responsabilidades frente às mudanças climáticas globais por frequentadores de uma praça urbana na cidade do Rio de Janeiro (RJ, Brasil) e o papel das fontes de informação. In: ENCONTRO NACIONAL DE PROGRAMAS DE PÓS-GRADUAÇÃO E PESQUISA EM AMBIENTE E SOCIEDADE, ENAMPPAS, 7., 2015, Brasília. Anais... Disponível em: < http:/ /icongresso. itarget.com.br/tra/arquivos/ann.2/290.pdf >. Acesso em: 9 set. 2016.

Percepções sobre o meio ambiente e o mar por interessados em ecoturismo marinho na área de proteção ambiental marinha de Armação de Búzios, estado do Rio de Janeiro, RJ, Brasil. Pesquisa em Educação Ambiental, Rio Claro, v. 8, n. 2, p. 59-75, 2013. Disponível em: <http://www.periodicos.rc.biblioteca.unesp.br/index.php/pesquisa/article/ view/6933/6029>. Acesso em: 9 set. 2016. 
Percepção ambiental sobre as mudanças climáticas globais ...

REIGOTA, M. Meio ambiente e representação social. 7. ed. São Paulo: Cortez, 2007.

SAITO, C. H. Popularizando o Probio: educação ambiental na praça e na escola. Revista Brasileira de Educação Ambiental, Rio Grande, v. 7, n. 2, p. 83-95, 2012. Disponível em: <http://www.sbecotur.org.br/revbea/index.php/revbea/article/viewFile/2025/2261>. Acesso em: 27 fev. 2015.

SAITO, C. H.; FIGUEIREDO, J.; VARGAS, I. A. Educação ambiental freireana no contexto de formação de educadores ambientais. In: PEDRINI, A. G.; SAITO, C. H. (Org.). Paradigmas metodológicos em educação ambiental. Petrópolis: Vozes, 2014. p. 71-81.

SILVA, R. L. et al. Educação ambiental, mudanças climáticas e ensino de biologia: análise de concepções e processo de produção de um jogo para o ensino médio. Revista da SBEnBIO, Niterói, v. 3, p. 3491-3501, 2010.

SOUZA, M. A. O aquecimento global e sua repercussão na mídia: algumas contribuições para um debate. GeoAtos, Presidente Prudente, v. 2, n. 12, p. 91-104, 2012. Disponível em: $<$ http://revista.fct.unesp.br/index.php/geografiaematos/article/view/1818/marcos>. Acesso em: 19 set. 2016.

STURMER, A. B.; TREVISOL, J. V.; BOTON, E. A. Aquecimento global: percepções dos estudantes do ensino médio. Unoesc \& Ciência-ACHS, Joaçaba, v. 1, n. 1, p. 21-28, jan/ jun. 2010. < http://editora.unoesc.edu.br/index.php/achs/article/view/178>. Acesso em: 19 set. 2016.

TAVARES, A. C. et al. Aquecimento global e mudanças climáticas na visão de estudantes do ensino médio. CLIMEP: climatologia e estudos da paisagem, Rio Claro, v. 5, n. 1, p. 100-116, 2010. Disponível em: <http://www.periodicos.rc.biblioteca.unesp.br/index.php/ climatologia/article/view/4180/3377>. Acesso em: 19 set. 2016.

TRENOUTH, A. L. et al. Public perception of marine and coastal protected areas in Tasmania, Australia: importance, management and hazards. Ocean \& Coastal Management, Amsterdam, v. 67, p. 19-29, 2012.

TURRA, A. et al. Global environmental changes: setting priorities for Latin American coastal habitats. Global Change Biology, Chichester, v. 19, n. 7, p. 1965-1969, 2013.

VASCONCELLOS, F. A. L.; AMARAL, F. D.; STEINER, A. Q. Student's view of reef environments in the metropolitan area of Recife, Pernambuco state, Brazil. Arquivos de Ciências do Mar, Fortaleza, v. 4, n. 1, p. 104-112, 2008.

Artigo recebido em 01/04/2015. Aceito em 25/01/2016.

Endereço para contato: UERJ, Rua São Francisco Xavier, 524, Pavilhão Haroldo Lisboa da Cunha, sala 525, Campus Maracanã, CEP 20550-001, Rio de Janeiro, RJ, Brasil. 


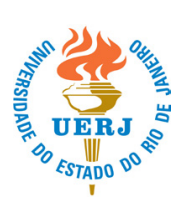

Anexo 1. Questionário aplicado para coleta dos dados

Universidade do Estado do Rio de Janeiro

Instituto de Biologia Roberto Alcântara Gomes

Departamento de Biologia Vegetal

Projeto: Percepção e Educação Ambiental em Praça Pública contra o Aquecimento Global no Mar Questionário de Percepção Ambiental

\section{Perfil do Respondente}

Nome (primeiro nome e último sobrenome):

Data de nascimento: / / . Bairro de Moradia:

Profissão: Cidade/Estado de nascimento:

Frequência na praça em 2013/2014: ( ) acima de 5 vezes; ( ) abaixo de 5 vezes. Por que?

Vem sempre (ou quase) nessa Feira "Desapegue-se”? ( ) Não ; ( ) Sim. Por que?

Como tomou conhecimento da feira "Desapegue-se"? ( ) Internet; ( ) Amigos e/ou familiares; ( ) Jornal e/ou revistas; ( ) Panfleto na rua; ( ) Outro:

Faixa Salarial em salários mínimos (R \$724,00): ( ) Até 1 salário; ( ) De 2-5 salários; ( ) De 6-10 salários; ( ) Acima de 11 salários; ( ) Não tem:

Escolaridade:

\section{Questões Técnicas (Sublinhe apenas uma resposta e use o verso da folha, se necessário) O que você entende por:}

Ambiente: (a) local da espécie humana; (b) local da natureza; (c) local de todos, (d) outro:

Educação Ambiental: (a) palestras sobre meio ambiente; (b) dinâmicas sobre o meio ambiente; (c) processo pedagógico para mudar os hábitos das pessoas; (d) processo pedagógico que proporcione emancipação política e financeira dos homens; (e) outra:

Mar: (a) paisagem relaxante; (b) ambiente com água salgada para o lazer; (c) ambiente com seres vivos, água, rochas, areias, interagindo; (d) outro entendimento:

Mudanças Climáticas Globais (MCGs): (a) alterações no planeta Terra de causa desconhecida; (b) alterações no clima da Terra causadas pela poluição aquática; (c) alterações no clima causadas pelo lançamento na atmosfera de gases maléficos, do desmatamento e incêndios florestais; (d) outro:

Aquecimento Global: (a) aumento da temperatura da Terra causada pela poluição no mar; (b) alteração da temperatura da água do mar; (c) aumento da temperatura no mundo devido às MCGs; (d) outro:

\section{Sublinhe suas duas principais fontes de informação cotidianas:}

TV comum; TV por assinatura; Jornal de banca; Internet, Periódicos de divulgação científica; periódicos para cientistas, revistas de divulgação científica disponíveis em bancas de jornais; livros técnicos, familiares; filmes no cinema; outras:

E-Mail:

Telefone:

\section{Escreva o que desejar:}

OBS: Esse questionário é para ser respondido por uma só pessoa com a finalidade de identificar o conhecimento que os frequentadores dessa praça possuem sobre as Mudanças Climáticas Globais com o fim de capacitá-lo posteriormente como cidadão para o enfrentamento urgente dessa problemática 